\title{
Effects of syntactic prominence on eye movements during reading
}

\author{
STACY BIRCH \\ State University of New York, Brockport, New York \\ AND \\ KeITH RAYNeR \\ University of California, San Diego, La Jolla, California
}

\begin{abstract}
Three experiments explored whether patterns of eye movements during reading might help explain syntactic prominence effects that are typically observed using reaction time tasks. Participants read sentences in which target words were in syntactically prominent or syntactically less prominent positions. Across all three experiments, using three types of syntactic prominence manipulations, there were fewer fixations and shorter reading times for words in more prominent positions, indicating that enhanced accessibility of syntactically prominent words is not caused by increased processing time. Rather, syntactic prominence appears to facilitate early encoding/lexical access and sentence integration processes while also, as shown previously, increasing activation of concepts in a comprehender's sentence or discourse representation. We propose that enhanced encoding and sentence integration processes can be attributed to an increase in attentional resources for more prominent concepts, and that this increase derives from readers' immediate sensitivity to informational prominence contours that are signaled by syntax.
\end{abstract}

One of the functions of a sentence's syntactic structure is to indicate the relative importance of referents within the sentence. This indication of importance or prominence can serve as "mental processing instructions" (Givón, 1992) for a reader or listener to pay more attention to entities that are marked as important by sentence structure. Although there are several ways of indicating importance in spoken and written language, including prosodic emphasis (Hirotani, Frazier, \& Rayner, 2006) and focus particles such as only (Paterson et al., 2007), we will focus here primarily on syntactic manipulations of prominence.

We use the term syntactic prominence in the same way as did McKoon, Ratcliff, Ward, and Sproat (1993), whose study was an important precursor to the present study. According to McKoon, Ratcliff, et al., the idea that syntax can indicate importance or salience is based on both linguistic analyses and empirical results. On the basis of linguistic analyses, Wilson and Sperber (1979) proposed that, depending on the complexity of a sentence, "there is an indefinite number of levels of prominence" (p. 306) among the sentence's constituents, and that these levels of prominence can be "ordered" by syntactic structure. For instance, they indicated that a focus structure such as an itcleft assigns greater prominence to constituents than does main-clause position, which in turn assigns greater prominence than does subordinate-clause position. McKoon, Ratcliff, et al. noted that some psychological models of discourse processing (e.g., Kintsch, 1974) have also incorporated the notion that concepts are "ordered in terms of importance" (p. 594) by surface structure. The various syntactic indicators of prominence or salience result in heightened "status" for the more prominent sentence constituents (cf. McKoon, Ratcliff, et al., 1993, pp. 594-595). This heightened status enhances processing during language comprehension. ${ }^{1}$ In the present study, we further explored processing differences between pairs of more prominent versus less prominent sentence constituents.

A number of studies have shown that variations in syntactic structure affect several aspects of language processing. For instance, syntactic prominence enhances the speed and accuracy of perceiving and remembering referents of prominent concepts (Birch, Albrecht, \& Myers, 2000; McKoon, Ratcliff, et al., 1993; Singer, 1976) along with their phonological and semantic characteristics (Birch \& Garnsey, 1995; Blutner \& Sommer, 1988; Sturt, Sanford, Stewart, \& Dawydiak, 2004; Ward \& Sturt, 2007). Making information more prominent also reduces the likelihood that readers will overlook a factual error (i.e., fall prey to the Moses illusion; Brédart \& Modolo, 1988; cf. Brédart \& Docquier, 1989) or will make an error in a proofreading or letter-detection task (Moravcsik \& Healy, 1998). Syntactic prominence also increases accuracy in identifying false assertions (Langford \& Holmes, 1979) and facilitates inference drawing (Gergely, 1992) and other 
integration processes (Morris \& Folk, 1998). Resolving anaphors is easier when antecedent information has been made more prominent (Foraker \& McElree, 2007; Garrod \& Sanford, 1994; Klin, Weingartner, Guzmán, \& Levine, 2004; McKoon, Ward, Ratcliff, \& Sproat, 1993).

Thus, syntactic prominence leads to a number of processing advantages, resulting in the proposal that prominent concepts have heightened activation in a comprehender's sentence or discourse representation (see, e.g., Kintsch, 1992; Myers \& O'Brien, 1998; see also Foraker $\&$ McElree, 2007, for a discussion of different classes of language-processing models that incorporate prominence effects). A number of the studies indicating heightened activation of prominent concepts have involved measuring effects following the presentation of prominent or less prominent information, such as with probe recognition, lexical decision, or anaphor resolution. In the present study, we focused on the initial processing of prominent versus less prominent concepts themselves, which Morris and Folk (1998) referred to as "direct effects." In particular, we addressed the question of whether the heightened activation of prominent information that was found in previous studies is related to differences in the way prominent information is encoded in the first place.

A number of studies seem to indicate that prominent information itself is processed more quickly. For instance, Carpenter and Just (1977) used cleft sentences to manipulate prominence and found that readers directed their gaze to pictures of focused referents prior to directing it to nonfocused referents and were faster to identify inconsistencies involving the focused referents. Langford and Holmes (1979) found that readers were faster to verify false assertions in focused (clefted or pseudoclefted) portions of sentences, suggesting that prominence speeded processing. In a more direct comparison of encoding times using eye movements, Morris and Folk (1998) found no effect of focus (it-clefting) on first-pass reading time but found shorter total reading times and fewer regressions to focused items. They argued that their results indicate that focus does not affect lexical access but does facilitate text-integration processes for the prominent concepts. Ward and Sturt (2007) also measured eye movements but found no direct processing differences for words focused by a context question. They did find that a region prior to the target word was read faster in the focus condition; however, they pointed out that this result may have arisen, at least in part, because of repetition of a word from the focusing question. In the auditory domain, Cutler and Fodor (1979) found that listeners were faster to identify a target word's initial phoneme when that word had been placed in focus by a question preceding the target sentence.

Results from other studies seem to indicate that prominent information is processed more carefully or takes longer to process. Indeed, increased processing for prominent information would seem to be predicted by some theories of text processing, such as Kintsch's (1992) update of the construction-integration model (Kintsch, 1988), in which more prominent information has an increased likelihood of remaining in short-term memory over successive cycles of processing. McKoon, Ratcliff, et al. (1993) also sug- gested that increased prominence leads to increased attention, which is likely to be manifested in increased processing time. In their studies of focusing structures such as $i t$-clefts, Engelkamp and Zimmer (1982) proposed that prominent (new or focused) information "attracts more attention and is processed with greater intensity than the given information" (p. 465). They cited results from Zimmer and Engelkamp (1981) in support of this proposal, since comprehenders in that study spent more time looking at referents of information focused by it-clefts. As with the Carpenter and Just (1977) study cited previously, however, viewing time was for pictures presented immediately after the target concepts were presented, so the evidence for greater processing time was indirect. Increased accuracy in error detection is also consistent with more careful processing of prominent information (Brédart \& Modolo, 1988; Moravcsik \& Healy, 1998), but, again, the measure of processing time in these studies was somewhat indirect. Scinto (1978) did directly measure fixation durations of new and given information in text (in this case, a fable by Aesop). He found that fixations were longer for new information. His results thus suggest that, to the extent that new information is more prominent than given information, information prominence is associated with increased processing time. However, the given and new regions of information were not equated (e.g., in terms of word frequency, repetition, or syntactic position), so these results must be interpreted with caution. Finally, Birch and Rayner (1997) also found increased fixation times for focused words (using it-clefts, there-insertion, and focus questions) in two experiments, but primarily in secondpass rather than first-pass reading measures. First-pass reading times were longer only when an entire phrase was focused, rather than when a single word was, and only in Experiment 2, in which focus was manipulated by a question preceding the target sentence.

Thus, the evidence is conflicting as to whether comprehenders spend less or more time on the direct processing of prominent concepts than on the direct processing of less prominent concepts. The basic goal of the present study was to provide additional evidence on this question using eyetracking measures. A second goal of the study was to extend the study of direct processing effects to alternative syntactic manipulations of prominence. Most previous studies of direct processing effects used specialized linguistic focus devices, such as cleft structures, thereinsertion, or focus questions. For the present study, we began (Experiments 1 and 2) with relatively more subtle manipulations of prominence involving small changes in syntactic position of target concepts, as opposed to the addition of focusing phrases or sentences. The syntactic manipulations in these two experiments were the same as those used by McKoon, Ratcliff, et al. (1993) in their study of the effects of syntactic prominence on memory accessibility. In Experiment 3, we returned to the use of focusing phrases (cleft structures and there-insertion) to manipulate prominence. The manipulation in Experiment 3 thus followed the approach in Birch and Rayner (1997) and Morris and Folk (1998), except that our nonprominent condition was modified (additional details about 
each type of prominence manipulation will be provided in the introductions to the individual experiments). We thus compared the direct processing of prominent versus less prominent constituents across the experiments using three types of syntactic prominence manipulations.

In spite of the conflicting evidence on effects of prominence on eye movements, we did begin our study with a clear expectation. This expectation arose in part out of McKoon, Ratcliff, et al.'s (1993) study showing heightened accessibility of prominent concepts in both the short- and longer-term memory representation of discourses. They proposed that this increased accessibility likely arose from the translation of increased attention into increased processing during reading. In addition, our previous study of focus effects on eye movements (Birch $\&$ Rayner, 1997) seemed to support the notion that prominent information received more attention or longer processing during reading. We thus predicted in the present Experiments 1-3 that eyetracking measures would reveal longer processing times for prominent concepts than for less prominent concepts.

\section{EXPERIMENT 1}

In Experiments 1 and 2, we adopted the prominence manipulations-indeed, the very passages-utilized in McKoon, Ratcliff, et al.'s (1993) study of syntactic prominence effects. McKoon, Ratcliff, et al. described two syntactic variables that had been previously shown in linguistic analyses to affect the perceived prominence of constituents, and they developed their materials around them. The first, which they used in their Experiments 1-3, was used in our Experiment 1. This manipulation was based largely on work by Wilson and Sperber (1979), who discussed a number of syntactic forms that can "assign" differing degrees of importance to the constituents of sentences. Among the forms that they described as ordering prominence was position within a main clause versus within a modifying phrase. Wilson and Sperber argued that when two propositions are each expressed in separate main clauses (e.g., This book is boring, and it is expensive), the propositions are "naturally interpreted" to be "separate but equal pragmatic points" (p. 306). When one is expressed as a phrase (e.g., this boring book), however, it is "clearly subordinate" to the main-clause proposition. These examples come from Wilson and Sperber.

On the basis of Wilson and Sperber's (1979) analysis, McKoon, Ratcliff, et al. (1993) developed discourses in which a target concept varied according to whether it was within a main clause or within a modifying phrase. In Example 1 below, for instance, demanding is more salient or prominent when in a main clause (Version A) than when in a prenominal position (Version B):

\section{George is having second thoughts about his new job.}

\section{A. His critical boss is demanding at times.} versus

B. His demanding boss is critical at times.

\section{George is thinking of quitting.}

(Likewise, when critical is in the predicate position, as in Version B, it is more prominent than when it is prenominal, as in Version A.) McKoon, Ratcliff, et al. presented discourses such as these and found faster probe recognition times for target words in the predicate than in the prenominal position. We presented readers with these discourses in order to compare eye movement patterns for the prominent and nonprominent concepts.

\section{Method}

Participants. The participants were 32 University of Massachusetts students participating for course credit or pay. All had normal or corrected-to-normal vision.

Materials and Design. There were two sets (A and B) of 24 passages, each of which consisted of three sentences. The second sentence in each passage was the critical sentence, in which prominence of target concepts was manipulated, on the basis of whether they appeared in the predicate (prominent) or prenominal position. Each target appeared in both the prominent and nonprominent versions so that comparisons between the two were of the same words, but the two versions of each target word were placed on separate lists. Set A and Set B passages differed only according to which target words were in which position in the second sentence. In Example 1, for instance, demanding was in the prominent position and critical was in the nonprominent position in Set A, whereas critical was in the prominent position and demanding was in the nonprominent position in Set B. Each target word appeared only once on each list (in prominent position for half the participants and in nonprominent position for the other half), and each participant read only one list. There were 72 two-sentence filler passages that differed in pattern from the experimental sentences.

Apparatus and Procedure. Each participant was seated in front of a Sony Trinitron 1302 video monitor, with his or her mouth resting on a bite bar to eliminate head movements. Eye movements were monitored via a Fourward Technologies Dual Purkinje Generation V eyetracker. The eyetracker had a resolution of less than 10' of arc and was interfaced with an Epson Equity III computer, which controlled text presentation. Participants read 6 warm-up passages and then 96 experimental and filler passages. In this experiment and the two subsequent experiments, the sentences making up the passages appeared in standard passage format (i.e., all sentences were presented together at one time, without each sentence beginning a new line). Participants read each passage at their own pace while the movements of their right eye were monitored by the eyetracker. They pushed a lever on a response box after reading each item. Following approximately $25 \%$ of the trials, there was a comprehension question to which participants answered yes or no by pressing different levers. All participants answered these questions accurately $85 \%$ of the time or more. The experiment lasted approximately $40 \mathrm{~min}$.

\section{Results}

A number of eye movement measures were computed for the target words in the prenominal versus predicate (prominent) position. Measures are reported for the target region only, because all other regions of the passages in the different conditions were identical. Specifically, we examined first-fixation time (i.e., the duration of the first fixation on the target word) and gaze duration (the sum of all fixations on the target word prior to an eye movement out of the region) as measures of initial processing. These measures are thought to largely indicate processes such as perceptual encoding and lexical access (see Ehrlich \& Rayner, 1983; Rayner, 1998, 2009), though they can also 
be influenced by nonlexical factors (Rayner, 2009). We also examined the percentage of regressions out of the target region, the percentage of regressions into the region, total number of fixations, second-pass time, and total reading time as measures of higher level processes (Ehrlich \& Rayner, 1983; Rayner, 1998, 2009). These measures are thought to largely reflect integration of a target region with other parts of the sentence and within the reader's discourse model. ${ }^{2}$ First-fixation times, gaze durations, and total reading times excluded trials for which there were no first-pass fixations; second-pass times included nonregressions as 0 -msec durations in means. Regressions out indicated the percentage of trials in which one or more first-pass fixations in the region were immediately followed by a fixation to an earlier point in the sentence, and regressions in indicated the percentage of trials in which one or more fixations in the region were preceded by a fixation in a later region of the sentence. Fixations less than $100 \mathrm{msec}$ or greater than $1,000 \mathrm{msec}$ (outliers) were eliminated. For both the initial-processing and integration measures of eye movements, we calculated means for each condition by participants and by items and computed participant $\left(F_{1}\right)$ and item $\left(F_{2}\right)$ ANOVAs.

Initial ANOVAs indicated that item set generally did not interact with prominence; in the one measure where it did interact, regressions out, the effect of prominence was simply more pronounced for one of the item sets. Thus, we report means collapsed across item sets for all measures. Results are shown in Table 1. First-fixation time, gaze duration, total reading time, and total number of fixations were all significantly greater in the nonprominent condition (when the adjective was in prenominal position) than in the prominent (predicate) condition. For first-fixation time, the effect of prominence was significant $\left[F_{1}(1,31)=\right.$ $\left.13.43, p<.001 ; F_{2}(1,23)=11.04, p<.01\right]$. The same result occurred for gaze duration $\left[F_{1}(1,31)=15.4, p<\right.$ $\left..001 ; F_{2}(1,23)=20.1, p<.001\right]$. Thus, prominent concepts were read more quickly for both early processing measures.

The remaining measures largely reflected integration processes. For total reading time, the effect of prominence was significant $\left[F_{1}(1,31)=22.8, p<.001\right.$; $\left.F_{2}(1,23)=18.8, p<.001\right]$. For total number of fixations, the effect of prominence was significant by participants $\left[F_{1}(1,31)=4.7, p<.05\right]$ and marginally significant by items $\left[F_{2}(1,23)=3.9, p=.06\right]$. For the remaining eye- tracking measures, there were no effects of prominence [regressions out, $F_{1}(1,31)=1.9, F_{2}(1,23)=1.9$; regressions in, all $F_{\mathrm{S}}<1$; second-pass time, all $\left.F_{\mathrm{S}}<1\right]$. Thus, on the basis of total reading time and number of fixations, prominent concepts were integrated into the discourse model more quickly than were less prominent concepts.

\section{Discussion}

Experiment 1 indicated that readers had shorter firstfixation times, gaze durations, and total reading times and made fewer total fixations on modifiers that were in the predicate position (e.g., critical in boss is critical) than on those same words when they were prenominal modifiers (e.g., critical in critical boss is). These results indicate, contrary to our original expectation, that readers processed the prominent modifiers more easily than the nonprominent modifiers. Indeed, given that both early measures of reading (first-fixation time, gaze duration) and late measures (total reading time, total number of fixations) showed this effect, the results suggest that both encoding and integration processes are facilitated for prominent words. Additional implications of encoding and integration effects will be discussed following the reports of Experiments 2 and 3.

As in any eyetracking study, it is important to assess the extent to which eye movements might have been affected by certain low-level differences between conditions. For instance, differences in context for the prominent and nonprominent conditions might have differentially affected the probability of skipping the target region. To assess this possibility, we compared the probability of fixating the prominent and nonprominent targets; the rate of fixation was high and did not differ between conditions (.94 for both). A potential problem with the materials in the present study that might affect eye movements is the covariance of prominence with sentence position. As McKoon, Ratcliff, et al. (1993) acknowledged, the prominent concept was always closer to the end of the second sentence in the discourses from their study, which we used here. Although the prominent concept was never the final word in the critical sentences (which should have prevented wrap-up processes from affecting the times for the target words), it is still possible that nearness to the end of the sentence affected eye movements. Note that to the extent that wrap-up processes might indeed begin slightly prior to sentence-final position, and thus affect the

Table 1

Time (in Milliseconds), Number of Fixations, and Percentage of Regressions (With Standard Deviations) by Prominence Condition in Experiment 1

\begin{tabular}{|c|c|c|c|c|c|c|c|c|c|c|c|c|c|c|}
\hline \multirow{2}{*}{$\begin{array}{l}\text { Prominence } \\
\text { Condition }\end{array}$} & \multicolumn{2}{|c|}{$\begin{array}{c}\text { First- } \\
\text { Fixation } \\
\text { Time }^{\dagger}\end{array}$} & \multicolumn{2}{|c|}{$\begin{array}{c}\text { Gaze } \\
\text { Duration }{ }^{\dagger}\end{array}$} & \multicolumn{2}{|c|}{$\begin{array}{c}\text { Regressions } \\
\text { Out }\end{array}$} & \multicolumn{2}{|c|}{$\begin{array}{l}\text { Regressions } \\
\text { In }\end{array}$} & \multicolumn{2}{|c|}{$\begin{array}{l}\text { Second-Pass } \\
\text { Time }\end{array}$} & \multicolumn{2}{|c|}{$\begin{array}{c}\text { Total } \\
\text { Number of } \\
\text { Fixations }{ }^{\dagger}\end{array}$} & \multicolumn{2}{|c|}{$\begin{array}{c}\text { Total } \\
\text { Reading } \\
\text { Time }^{\dagger}\end{array}$} \\
\hline & $M$ & $\overline{S D}$ & $M$ & $\overline{S D}$ & $M$ & $\overline{S D}$ & $M$ & $S D$ & $M$ & $\overline{S D}$ & $M$ & $S D$ & $M$ & $S D$ \\
\hline $\begin{array}{l}\text { Prenominal } \\
\quad \text { (e.g., critical boss) }\end{array}$ & 288 & 39 & 396 & 87 & 13.02 & 16 & 15.02 & 13 & 64.84 & 86 & 1.66 & 0.41 & 468 & 120 \\
\hline $\begin{array}{l}\text { Predicate/prominent } \\
\text { (e.g., boss is critical) }\end{array}$ & 271 & 44 & 352 & 80 & 9.60 & 13 & 13.48 & 12 & 59.60 & 62 & 1.60 & 0.35 & 416 & 108 \\
\hline
\end{tabular}

Note-Target word in italics. †Significant effect of prominence. 
target word when in the prominent (predicate) position, the most likely result would be an increase in number or duration of fixations (Rayner, 1998). The opposite effect was found for prominent target words, so early sentence wrap-up processes are unlikely to explain our results. It could be, however, that proximity to the beginning of the line rather than prenominal position per se produced increased processing times for the nonprominent condition. Because fixation durations following return saccades tend to be longer than those that do not follow return saccades (Rayner, 1998), longer processing times could occur for constituents just because they are very near the beginning of a line. For most of the passages in Experiment 1, the prenominal modifier was the second word on the second line, a position that could have led to increased processing times. Therefore, it would be useful to replicate the effects found in Experiment 1 for prominent and nonprominent targets located in alternative sentence positions. This was accomplished in Experiment 2.

Another potential problem with the materials in Experiment 1 is that predicate and prenominal adjectives might receive differential processing in reading for reasons other than a difference in syntactic prominence. For instance, perhaps the parsing process differs for predicate and prenominal adjectives because of their different positions with respect to the head noun that they modify. In particular, the prenominal adjectives in Experiment 1 may have had longer encoding and integration times because they were processed together with the head noun that immediately followed them. Given that the average target-word length was 7.9 letters (range of 4 to 13), it seems unlikely that readers would have generally fixated the adjective and noun at the same time. For shorter adjectives (e.g., rich, inane), however, readers may well have done so in the prenominal condition. In any case, it would be useful to replicate the effects observed in Experiment 1 with materials in which prominence is varied not by predicate versus prenominal position of an adjective but by an alternative variation of syntactic roles. Thus, in Experiment 2, prominent and nonprominent targets varied from those in Experiment 1 not only with respect to sentence location and proximity to the beginning of a line but also with respect to the types of syntactic role they filled.

\section{EXPERIMENT 2}

In Experiment 2, we employed the syntactic variation of salience used in McKoon, Ratcliff, et al.'s (1993) Experiment 4. Unlike in the present Experiment 1, where target words were adjectives in pre- and postnominal positions, targets in the present experiment were noun phrases with differing roles within a proposition. The syntactic variation involved different relationships of an argument to a verb. As McKoon, Ratcliff, et al. pointed out, work in functional syntax (e.g., Anderson, 1971) has shown that arguments in certain syntactic positions are more "affected" by the verb than are arguments in other positions. McKoon, Ratcliff, et al. specified that "the more affected a discourse entity is by the action of the verb as indicated by its syntactic position relative to the verb, the more prominent or salient will be its position in the discourse model" (p. 595). According to Anderson's analysis, an argument in the direct-object position is more affected by the verb than is an argument in the indirect-object position. ${ }^{3}$ Accordingly, McKoon, Ratcliff, et al. developed materials for use in their probe recognition task in which noun phrases varied according to whether they were in the direct-object versus indirect-object position. In Example 2 below, his trunk is more prominent when in the direct-object position (Version A) than when in the indirect-object position (Version B):

\section{Rex had lost his favorite marble.}

\section{A. He made his father move his trunk onto his dresser right before bedtime.}

versus

\section{B. He made his father move his dresser onto his trunk right before bedtime.}

His marble was not under the furniture.

(Likewise, his dresser is more prominent in Version B than in Version A.) McKoon, Ratcliff, et al. found that probe recognition times were faster for the targets in the direct-object position, providing empirical support for Anderson's analysis. In the present experiment, we measured readers' eye movements as they read discourses such as these in order to assess encoding effects for this prominence manipulation. Unlike in Experiment 1, the prominent condition came earlier in the sentence than did the nonprominent condition. Thus, the passages in this experiment enabled us to assess whether the effects of prominence observed in Experiment 1 arose from proximity to either end of the sentence. Also, in Experiment 2, the target concepts were noun phrases (NPs) rather than single-word modifiers, allowing enhanced generalizability of the prominence effects in Experiment 1.

\section{Method}

Participants. The participants were 24 University of Massachusetts students participating for course credit or pay. Each had normal or corrected-to-normal vision and had not participated in Experiment 1.

Materials and Design. The experimental materials were 28 passages from McKoon, Ratcliff, et al. (1993). There were two sets (A and B), each of which consisted of three sentences. The second sentence in each passage was the critical sentence, in which prominence of target concepts was manipulated, on the basis of whether they appeared as the direct (prominent) or indirect object of the verb. Each target appeared in both versions, on separate lists. In Example 2, for instance, his trunk was in the prominent position and his dresser was in the nonprominent position in Set A, whereas his dresser was in the prominent position and his trunk was in the nonprominent position in Set B. The determiners (e.g., his) were included in the measured target regions for this experiment. Each target appeared only once on each list (in prominent position for half the participants, in nonprominent position for the other half), and each participant read only one list. Filler passages were 72 three- or four-sentence discourses that departed from the pattern of the experimental passages.

Apparatus and Procedure. The apparatus and basic procedure were the same as those in Experiment 1. Participants read 6 warmup items and then 100 experimental and filler items. They read each item at their own pace while the movements of their right eye were monitored by the eyetracker. They pushed a lever after reading each 
item. Following approximately $25 \%$ of the trials, there was a comprehension question to which participants answered yes or no by pressing a lever on the response box; all participants achieved at least $85 \%$ accuracy on these questions. The experiment lasted approximately $45 \mathrm{~min}$.

\section{Results}

We compared the number and duration of fixations on the direct-object (prominent) position with those on the indirect-object position (e.g., his dresser and his trunk in Example 2). As in Experiment 1, we report measures for the target region (two words, in this case), including measures that largely reflect encoding or lexical access (firstfixation and first-pass reading times ${ }^{4}$ ) and measures that largely reflect integration processes (regressions out, regressions in, total number of fixations, second-pass time, and total reading time). Fixations less than $100 \mathrm{msec}$ or greater than $1,000 \mathrm{msec}$ were eliminated, and means for each condition were calculated for use in participant and item ANOVAs. The results, collapsed across item sets, are shown in Table 2. First-pass times, total reading times, and total number of fixations were significantly greater in the nonprominent condition than in the prominent condition.

Unlike in Experiment 1, there was no effect of prominence on first-fixation time $\left(F_{1}=1.5, F_{2}<1\right)$; however, the effect of prominence was significant for first-pass reading time $\left[F_{1}(1,23)=9.1, p=.006 ; F_{2}(1,27)=10.9\right.$, $p=.003]$. For total reading time, the effect of prominence was significant by participants $\left[F_{1}(1,23)=5.4, p=.03\right]$ and marginally significant by items $\left[F_{2}(1,27)=3.1, p=\right.$ $.09]$. For total number of fixations, the effect of prominence was significant by participants $\left[F_{1}(1,23)=8.1\right.$, $p=.009]$ and by items $\left[F_{2}(1,27)=5.1, p=.03\right]$. For the remaining measures, there were no significant effects of prominence (regressions out, $F \mathrm{~s}<1$; regressions in, $F_{\mathrm{s}}<1$; second-pass times, $F_{1}=2, p=.17 ; F_{2}=2.7$, $p=.11)$.

\section{Discussion}

In Experiment 2, readers spent less time on first-pass and total reading and made fewer total fixations on NPs that were in the direct-object position than on these same NPs when they were in the indirect-object position. These results essentially replicate the finding from Experiment 1 that readers needed less time to process prominent constit- uents. Although the effect of prominence did not replicate the result from Experiment 1 for first-fixation times, ${ }^{5}$ the effect for first-pass reading suggests that encoding and/or lexical access was faster for prominent constituents. The prominence effects for total reading time and total number of fixations suggest that integration processes were also easier for the prominent constituents. Since the prominent position for the passages from Experiment 2 was relatively closer to the beginning of the sentence (whereas it was closer to the end for Experiment 1), proximity to either end of the sentence is unlikely to explain the results. That is, the results are not consistent with the sentence wrap-up and return-saccade explanations previously described. As in Experiment 1, the probability of fixation was similar for the prominent and nonprominent targets in Experiment 2 (.97 and .96 for prominent and nonprominent targets, respectively). Thus, the observed effects also seem unlikely to be attributable to differences in skipping rates for the target regions.

Results from Experiments 1 and 2 thus indicate that for both types of syntactic manipulations used by McKoon, Ratcliff, et al. (1993) — predicate versus prenominal position and direct- versus indirect-object position-prominent concepts were encoded and integrated more quickly during reading. This pattern of results is opposite to what we expected on the basis of proposals in Kintsch's (1988, 1992) and McKoon, Ratcliff, et al.'s discussions of discourse processing. Moreover, the results are not consistent, at least not fully so, with previous studies of the effects of prominence on eye movements. For instance, in our previous study of focus effects on eye movements, second-pass reading times were longer for prominent concepts when it-clefts and there-insertion were used to convey prominence (Birch \& Rayner, 1997, Experiment 1; cf. Scinto, 1978). Our present results are consistent with those of Morris and Folk (1998), but only for total reading time, not for first-pass reading time. That is, our Experiments 1 and 2 support the conclusion from Morris and Folk that prominent concepts are integrated into a discourse representation more quickly but, unlike their results, ours also indicate that prominent concepts are encoded or accessed more quickly in the first place.

One possible source of divergence between the present and previous studies of direct-processing effects is the nature of the prominence manipulations. With the exception of Scinto (1978), whose materials were prob-

Table 2

Time (in Milliseconds), Number of Fixations, and Percentage of Regressions (With Standard Deviations) by Prominence Condition in Experiment 2

\begin{tabular}{|c|c|c|c|c|c|c|c|c|c|c|c|c|c|c|}
\hline \multirow{2}{*}{$\begin{array}{l}\text { Prominence } \\
\text { Condition }\end{array}$} & \multicolumn{2}{|c|}{$\begin{array}{l}\text { First- } \\
\text { Fixation } \\
\text { Time }\end{array}$} & \multicolumn{2}{|c|}{$\begin{array}{c}\text { First-Pass } \\
\text { Time }^{\dagger}\end{array}$} & \multicolumn{2}{|c|}{$\begin{array}{l}\text { Regressions } \\
\text { Out }\end{array}$} & \multicolumn{2}{|c|}{$\begin{array}{l}\text { Regressions } \\
\text { In }\end{array}$} & \multicolumn{2}{|c|}{$\begin{array}{l}\text { Second- } \\
\text { Pass } \\
\text { Time }\end{array}$} & \multicolumn{2}{|c|}{$\begin{array}{c}\text { Total } \\
\text { Number of } \\
\text { Fixations }{ }^{\dagger}\end{array}$} & \multicolumn{2}{|c|}{$\begin{array}{c}\text { Total } \\
\text { Reading } \\
\text { Time }^{\dagger}\end{array}$} \\
\hline & $M$ & $\overline{S D}$ & $M$ & $S D$ & $M$ & $\overline{S D}$ & $M$ & $\overline{S D}$ & $M$ & $\overline{S D}$ & $M$ & $\overline{S D}$ & $M$ & $\overline{S D}$ \\
\hline $\begin{array}{l}\text { Direct object/prominent } \\
\quad \text { (e.g., move his trunk) }\end{array}$ & 284 & 33 & 401 & 54 & 10.92 & 9 & 12.25 & 12 & 58.6 & 53 & 1.80 & 0.3 & 490 & 74 \\
\hline $\begin{array}{l}\text { Indirect object } \\
\quad \text { (e.g., onto his trunk) }\end{array}$ & 280 & 33 & 435 & 68 & 8.90 & 10 & 11.80 & 11 & 73.1 & 73 & 1.95 & 0.4 & 528 & 106 \\
\hline
\end{tabular}

Note-Target phrase in italics. †Significant effect of prominence. 
lematic, the previous eyetracking studies of prominence effects involved the use of focusing devices. In Birch and Rayner (1997), we used focusing phrases, $i t$-clefts and there-insertion (Experiment 1), and focus questions (Experiment 2) to place a word or phrase in focus. Morris and Folk (1998) used it-clefts, and Ward and Sturt (2007) used context questions to manipulate focus. According to Wilson and Sperber's (1979) analysis, focusing devices per se indicate prominence more clearly than do differences in syntactic position such as predicate versus prenominal modifier. Thus, it may be the case that the lack of complete correspondence between the present and previous eyetracking studies of prominence arises from our use of prominence manipulations that are subtler than focusing phrases. This possibility was assessed in Experiment 3 , in which we used focusing phrases to manipulate prominence.

The difference in type of syntactic manipulation is unlikely to be the only source of divergent results between the present and previous studies, however, since the results from eyetracking experiments on focus effects already diverged. A possible source of the divergent results among the previous studies is the nature of the nonfocus or nonprominent conditions with which the focus conditions were compared. Analysis of materials from the previous eyetracking studies suggests that additional differences between the comparison conditions besides the presence versus absence of a focusing device may have led to differential outcomes. In Birch and Rayner's (1997) Experiment 1 , the nonfocus condition consisted of sentences that not only eliminated the it-cleft or there-insertion phrases from the focus condition but also served to "bury" the target word to further reduce its prominence. In Example 3, for instance, suburb is focused in Version A and is deemphasized in Version B:

\section{A. It was the suburb that received the most damage from the ice storm.}

versus

\section{B. Workers in the suburb hurried to restore power after the ice storm.}

In Birch and Rayner's Experiment 2 and in Ward and Sturt (2007), focus was manipulated by a prior context sentence that contained an explicit (Birch \& Rayner, 1997) or embedded (Ward \& Sturt, 2007) question that focused a target word or phrase. For both experiments, the comparison condition was not the lack of any question, but rather an alternative question that focused a different target word or phrase. In some cases, the focus and nonfocus questions also differed in the presence versus absence of a word that was repeated in the target sentence. For instance, in Example 4, taken from Ward and Sturt, seat is contained in both the question and the target sentence in the focus condition (Version A, which focuses the target word exit), but it is only in the target sentence in the nonfocus condition (Version B):

\section{A. I couldn't decide which seat to take at the theatre.}

versus

B. I couldn't decide whether I liked the new theatre layout.

I hoped the seat by the exit would give me a good view.

(Note, too, that word repetition occurred in the nonfocus condition but not in the focus condition in Scinto's [1978] materials.) Finally, in Morris and Folk's (1998) experiment, the nonfocus condition involved not only the removal of the it-cleft preceding the target word, but also the presence of a subordinate clause and the presence of an it-cleft preceding an alternative word. For instance, in Example 5 below, taken from Morris and Folk's materials, the target concept waiter is focused by an it-cleft in Version A and is placed in a subordinate clause for the nonfocus condition (Version B):

\section{A. It was the waiter who watched while the ac- countant balanced the ledger a second time.} versus
B. While the waiter watched, it was the accountant who balanced the ledger a second time.

On the basis of Wilson and Sperber's (1979) analysis, concepts in subordinate-clause positions are less prominent than those in main-clause positions, so it would seem that waiter in Version B is not only removed from the explicit focus position but is also relatively de-emphasized by placement within a subordinate clause.

Thus, in each of the previously described eyetracking studies of prominence effects, there were additional differences between comparison conditions-besides the presence versus absence of a focusing device - that may have contributed to differential outcomes. Support for this proposal comes from results of a previous probe recognition study that explicitly tested whether differences in nonfocus comparison conditions could produce different outcomes. Birch et al. (2000) compared focus conditions (it-cleft or there-insertion) with two types of nonfocus conditions. One nonfocus condition was similar to that in Birch and Rayner's (1997) Experiment 1, in which the target concept was syntactically de-emphasized; the other was a "neutral" condition that was identical to the focus condition except for the removal of the focus phrase. Example 6 shows the target word mayor in the focus (Version A), nonfocus (Version B), and neutral (Version C) conditions:

\section{A. It was the mayor who refused to answer a re- porter's question.}

B. The reporter's question to the mayor was not answered.
C. The mayor refused to answer a reporter's question.

Birch et al. found that when immediate probe recognition was the dependent measure, response times to mayor were faster for the focus condition only when compared with the nonfocus condition, not when compared with the 
neutral condition. ${ }^{6}$ In fact, immediate probe recognition times were faster for targets in the neutral condition than for those in the nonfocus condition as well, indicating an inhibitory effect of syntactic de-emphasis. These results support the possibility that additional differences between prominent and nonprominent conditions - besides the use of a focusing phrase - affected direct processing times in previous eyetracking studies of prominence effects.

The foregoing discussion indicates the need to assess direct processing effects of focus using a neutral nonfocus comparison condition such as the one shown in Version C in Example 6. Experiment 3 provides this assessment. Additionally, the use of focus-nonfocus comparison conditions such as those exemplified in Versions $\mathrm{A}$ and $\mathrm{C}$ in Example 6 allows an additional validity test for the prominence effects observed in Experiments 1 and 2. Even though the effects replicated across two types of syntactic prominence manipulations (involving different sentence positions for the prominent concepts), it could be argued that role differences between conditions affected processing times for concepts in these experiments. That is, perhaps encoding or integration effects differ for predicate versus prenominal adjectives or for direct versus indirect objects because of parsing differences that are not directly attributable to syntactic prominence. Therefore, a comparison in which the target word's role is held constant between the prominent and nonprominent conditions would be useful. This type of comparison was also afforded by Experiment 3.

\section{EXPERIMENT 3}

Three primary goals for Experiment 3 emerged from the preceding discussion. The first was to determine whether the faster encoding and integration effects observed for prominent concepts in Experiments 1 and 2 could be replicated using explicit focusing phrases as the prominence manipulation. Second, we wanted to use a nonfocus condition that differed from the focus condition only by the removal of the focusing phrase, not by a shift of focus to alternative words or by syntactic de-emphasis of target words, as was done in previous eyetracking studies. Finally, we also wanted to use target words that held the same role in the prominent and nonprominent conditions, to assess whether the effects observed in Experiments 1 and 2 could be attributable to role differences between the conditions.

Experiment 3 consisted of two subexperiments, Experiment $3 \mathrm{~A}$ and $3 \mathrm{~B} .{ }^{7}$ For our present purpose of assessing direct effects of prominence on encoding and integration processes, Experiments $3 \mathrm{~A}$ and $3 \mathrm{~B}$ provided two tests of the same prominence manipulations - namely, it-clefts and there-insertion. According to Wilson and Sperber's (1979) work on the ordering of syntactic structures, such focusing devices are particularly compelling indicators of prominence. Indeed, the focus of a sentence as marked by such structures as $i t$-clefts and there-insertion has been defined as the most important and most emphasized (i.e., the most prominent) constituent in the sentence (Halliday, 1967; Rochemont \& Culicover, 1990). Accordingly, the focus structures that were used in Experiment 3 may be stronger indicators of prominence than are mainclause (Experiment 1) or direct-object (Experiment 2) position.

In both Experiments 3A and 3B, for both types of focus devices, the nonfocus condition was similar to the neutral condition illustrated in Example 6, Version C. In Example 7 below (which shows a passage from Experiment 3A), the target word landlady is made more prominent in Version A via it-clefting than in the neutral nonfocus condition in Version B:

7. The tenants at the complex were sick and tired of all the noise coming from \#204.

\section{A. It was the landlady who confronted the woman who lived there.}

versus

\section{B. The landlady confronted the woman who lived there.}

She evicted the woman finally, to everyone's relief.

Using discourses such as these, Birch et al. (2000) found evidence for enhanced accessibility of and memory for targets in the focus relative to the neutral nonfocus condition, as measured by sentence-continuation and delayed probe recognition tasks. In Experiments $3 \mathrm{~A}$ and 3B, we measured readers' eye movements to determine whether there were encoding differences for the two conditions.

\section{Method}

Participants. The participants were 24 University of Massachusetts students participating for course credit or pay. Each had normal or corrected-to-normal vision and had not participated in Experiment 1, but all had participated in Experiment 2.

Materials and Design. In both Experiments $3 \mathrm{~A}$ and 3B, there were two versions each of 24 passages (many of which were derived from Garrod, Freudenthal, \& Boyle, 1994). Each passage consisted of three to four sentences of varying lengths. Example 7 above shows a passage from Experiment $3 \mathrm{~A}$, and the following Example 8 shows a passage from Experiment $3 \mathrm{~B}$ :

8. A couple was having a romantic anniversary dinner. Unfortunately, the staff at the restaurant were rude and clumsy.

A. There was this waitress who spilled wine on the wife's dress.

versus

B. A waitress spilled wine on the wife's dress.

She complained loudly and asked for the manager.

As illustrated in both examples, the second or third sentence of each passage introduced two characters (typically of the same gender). The first or primary character (e.g., landlady in Example 7) was introduced within a syntactic focusing structure (either there was this or it was) in the prominent condition (Version A). This character was introduced with a determiner ( $a$, an, or the) in the nonprominent condition. The secondary character (e.g., woman in Example 7) was never introduced with a focusing phrase. The next sentence contained a pronominal reference to one of the two characters in the preceding sentence. In Experiment 3A, the pronoun referred to the primary character from the antecedent sentence (landlady in Example 7). In Experiment $3 \mathrm{~B}$, the pronoun referred to the secondary character (wife in Example 8). Because the primary and secondary characters were 
typically of the same gender, the reference needed to be inferred from the verb that followed the pronoun; this verb was consistent with the actions of the primary character in Experiment $3 \mathrm{~A}$ and consistent with the actions of the secondary character in Experiment 3B. There were no other differences in type between the two sets of materials; for our present purposes, the two sets of materials afforded an opportunity to replicate the effects of focus on the target words across the two subexperiments. As in Experiments 1 and 2, each target (the primary character in the penultimate sentence) appeared in both the focus and nonfocus versions, but on separate lists, and each participant read only one list. Unlike in Experiment 2, determiners were excluded in the measured target regions for this experiment.

In addition to the experimental passages, there were 76 filler passages (28 of which were the passages from Experiment 2), all of which were three sentences long, and none of which contained syntactic focusing phrases or ambiguous pronouns.

Apparatus and Procedure. The apparatus and procedure were the same as those in Experiments 1 and 2. Participants read 6 warmup items and then read the 100 experimental and filler items. They read each item at their own pace while their right eye movements were monitored by the eyetracker. They pushed a lever after reading each item and answered a comprehension question when it appeared (after approximately $25 \%$ of the passages). All participants achieved at least $85 \%$ accuracy on these questions.

\section{Results}

We compared number and duration of fixations on focused versus nonfocused target words (e.g., landlady in Example 7). As in Experiments 1 and 2, we report measures largely reflecting encoding or lexical access (firstfixation time and gaze duration) and measures largely reflecting integration processes (regressions out, regressions in, total number of fixations, second-pass time, and total reading time). Fixations less than $100 \mathrm{msec}$ or greater than 1,000 msec were eliminated, and means for each condition were calculated by participants and by items for use in participant and item ANOVAs. Because results did not vary by type of focusing phrase (there-insertion and itclefting), and because the materials were not designed to investigate differences between the two, we present only the combined results; these are shown in Table 3. Summarizing the details that follow, first-fixation time, gaze duration, total reading time, and total number of fixations were significantly reduced in the prominent relative to the nonprominent condition for both Experiments $3 \mathrm{~A}$ and 3B. In Experiment 3B alone, there were also more regressions out of the target region in the prominent condition.
In Experiment $3 \mathrm{~A}$, the effect of prominence on first-fixation time was significant by participants $\left[F_{1}(1,23)=9.4, p<.01\right]$ and marginally significant by items $\left[F_{2}(1,23)=3.3, p=.08\right]$ and was significant by both participants $\left[F_{1}(1,23)=10.8, p<.01\right]$ and items $\left[F_{2}(1,23)=7.5, p=.01\right]$ in Experiment $3 \mathrm{~B}$. For gaze duration, the effect of prominence was significant by both analyses in both Experiment $3 \mathrm{~A}\left[F_{1}(1,23)=40.5, p<\right.$ $\left..001 ; F_{2}(1,23)=19.4, p<.001\right]$ and Experiment $3 \mathrm{~B}$ $\left[F_{1}(1,23)=17.9, p<.001 ; F_{2}(1,23)=44, p<.001\right]$. Thus, for both measures, prominent concepts were read more quickly. These results replicate those regarding early processing from Experiments 1 and 2.

For total reading time, the effect of prominence was significant by participants and by items in both Experiment $3 \mathrm{~A}\left[F_{1}(1,23)=28.1, p<.001 ; F_{2}(1,23)=17\right.$, $p<.001]$ and Experiment $3 \mathrm{~B}\left[F_{1}(1,23)=7.5, p=.01\right.$; $\left.F_{2}(1,23)=17, p<.001\right]$. For total number of fixations, the effect of prominence was significant by both participants and items in Experiment $3 \mathrm{~A}\left[F_{1}(1,23)=11.2, p<\right.$ $\left..01 ; F_{2}(1,23)=9.3, p<.01\right]$ and marginally significant by participants and significant by items in Experiment $3 \mathrm{~B}$ $\left[F_{1}(1,23)=4.1, p=.06 ; F_{2}(1,23)=8.7, p<.01\right]$. For regressions out, there was no effect of prominence in Experiment $3 \mathrm{~A}\left(F_{1}<1.6, F_{2}<1.6\right)$, but there was a significant effect in Experiment $3 \mathrm{~B}\left[F_{1}(1,23)=12.1, p<\right.$ $\left..01 ; F_{2}(1,23)=22.5, p<.001\right]$. For regressions in, there were no significant effects of prominence in either Experiment $3 \mathrm{~A}($ all $F \mathrm{~s}<1)$ or Experiment $3 \mathrm{~B}\left[F_{1}(1,23)=\right.$ $\left.1.2, p=.28 ; F_{2}(1,23)=2.1, p=.16\right]$. For second-pass time, there were also no effects of prominence in either Experiment $3 \mathrm{~A}$ or $3 \mathrm{~B}($ all $F \mathrm{~s}<1)$.

\section{Discussion}

With one exception, regressions out, the results from both Experiments 3A and 3B essentially matched the results from Experiments 1 and 2. The pattern of means for regressions out - that there were more in the prominent condition - was the same in both Experiments 2 and $3 \mathrm{~A}$ as well; the difference was simply more extreme for Experiment 3B. This result may indicate an increased tendency to reread earlier text upon encountering syntactically prominent constituents. Alternatively, perhaps the focus sentences in Experiment 3B appeared somewhat unnatu-

Table 3

Time (in Milliseconds), Number of Fixations, and Percentage of Regressions (With Standard Deviations) by Prominence Condition in Experiments 3A and 3B

\begin{tabular}{|c|c|c|c|c|c|c|c|c|c|c|c|c|c|c|}
\hline \multirow{2}{*}{$\begin{array}{l}\text { Prominence } \\
\text { Condition }\end{array}$} & \multicolumn{2}{|c|}{$\begin{array}{c}\text { First- } \\
\text { Fixation } \\
\text { Time }^{\dagger}\end{array}$} & \multicolumn{2}{|c|}{$\begin{array}{c}\text { Gaze } \\
\text { Duration }{ }^{\dagger} \\
\end{array}$} & \multicolumn{2}{|c|}{$\begin{array}{c}\text { Regressions } \\
\text { Out }{ }^{\dagger \dagger} \\
\end{array}$} & \multicolumn{2}{|c|}{$\begin{array}{l}\text { Regressions } \\
\text { In } \\
\end{array}$} & \multicolumn{2}{|c|}{$\begin{array}{l}\text { Second- } \\
\text { Pass } \\
\text { Time }\end{array}$} & \multicolumn{2}{|c|}{$\begin{array}{c}\text { Total } \\
\text { Number of } \\
\text { Fixations }{ }^{\dagger}\end{array}$} & \multicolumn{2}{|c|}{$\begin{array}{c}\text { Total } \\
\text { Reading } \\
\text { Time }^{\dagger}\end{array}$} \\
\hline & $M$ & $S D$ & $M$ & $S D$ & $M$ & $S D$ & $M$ & $S D$ & $M$ & $S D$ & $M$ & $S D$ & M & $S D$ \\
\hline \multicolumn{15}{|c|}{ Experiment $3 \mathrm{~A}$} \\
\hline Focus (prominent) & 273 & 31 & 323 & 44 & 8.6 & 10.2 & 5.8 & 8.3 & 22.8 & 24.2 & 1.3 & 0.17 & 348 & 43 \\
\hline Neutral nonfocus (nonprominent) & 291 & 38 & 387 & 62 & 5.9 & 9.1 & 7.1 & 10.5 & 25.4 & 40.2 & 1.5 & 0.27 & 415 & 72 \\
\hline \multicolumn{15}{|c|}{ Experiment 3B } \\
\hline Focus (prominent) & 273 & 40 & 327 & 47 & 12.5 & 11.7 & 4.6 & 7.3 & 23.1 & 32.0 & 1.4 & 0.26 & 367 & 65 \\
\hline Neutral nonfocus (nonprominent) & 306 & 56 & 414 & 93 & 3.9 & 6.6 & 7.1 & 8.5 & 25.3 & 33.0 & 1.5 & 0.34 & 437 & 98 \\
\hline
\end{tabular}

†ignificant effects of prominence in both Experiment 3A and Experiment 3B. ††Significant effects of prominence in Experiment 3B only. 
ral to the readers, leading to an increased need to reread earlier regions. In any case, we believe it would be premature to attach much significance to this result, given that the effect was not reliable in Experiments 1, 2, and 3A. Moreover, there was no significant effect for this measure in Birch and Rayner (1997) or in Morris and Folk (1998). (This measure was not reported in the other two eyetracking studies of prominence, Scinto [1978] and Ward \& Sturt [2007].) Most importantly, in spite of the unusual result for regressions out in Experiment 3B, the results for the remaining measures of reading - including measures that reflect early encoding and text integration-were the same as those in Experiments 1, 2, and 3A.

As in Experiments 1 and 2, we performed follow-up analyses for Experiments $3 \mathrm{~A}$ and $3 \mathrm{~B}$ to assess whether certain low-level differences between conditions might have affected eye movements. We compared probabilities of fixation for target words in the two conditions and found them to be similarly high (.95 and .93 , respectively, for the nonprominent and prominent targets in Experiment $3 \mathrm{~A}$; .96 and .93 for the nonprominent and prominent targets in Experiment 3B). In addition, we assessed whether fixations for some target regions may have been affected by return saccades. As in Experiment 1, in a number of the passages in Experiments 3A and 3B, the target region for the nonprominent condition fell near the beginning of a line of text. As such, fixation durations for this region may have been longer due to the preceding return saccade. Although the results from Experiment 2 could not be attributed to an influence from return saccades, we wanted to assess this possible influence for Experiment 3. We therefore recomputed first-fixation time, gaze duration, total reading time, and total number of fixations for the subset of items in which the target region appeared in the middle of the line. As with the entire set of passages, first-fixation time, gaze duration, and total reading time were longer for nonprominent targets than for prominent targets. Although there was no difference in total number of fixations for this subset of items, the replication of results for the measures of reading time indicates that lineposition differences are unlikely to explain the obtained effects in Experiments 3A and 3B. ${ }^{8}$

Thus, with respect to the first goal for Experiment 3, the faster encoding and integration effects observed for prominent concepts in Experiments 1 and 2 were indeed replicated using explicit focusing phrases as the prominence manipulation. Since we used a nonfocus condition that differed from the focus condition only by the removal of the focusing phrase, we can be more confident that the observed effects were attributable to syntactic prominence, whereas the effects observed in previous eyetracking studies may have been influenced by syntactic de-emphasis in the nonfocus conditions or by other differences between the nonfocus and focus conditions. Finally, since target words held the same role in the prominent and nonprominent conditions in the present experiment, we can be confident that the effects observed in Experiments 1 and 2 were unlikely to be caused by role differences between the conditions.

\section{GENERAL DISCUSSION}

The purpose of the present study was to determine whether the heightened activation of and memory for prominent information that was observed in previous studies (e.g., Birch et al., 2000; McKoon, Ratcliff, et al., 1993) is related to differences in the way prominent information is encoded in the first place. We did find encoding differences, but not those that we expected. The results from three eyetracking experiments showed that readers spent less, not more, time processing prominent sentence constituents than they did processing less prominent constituents. That the prominence effects occurred for both initial and later processing measures indicates that prominence facilitated both early encoding/lexical access processes and integration processes during reading. Moreover, the prominence effects held across different item sets, across modifier and NP constituents, across early and late sentence positions, and across three types of syntactic manipulations of prominence.

The finding that prominence facilitated early encoding processes has not been previously reported in eyetracking studies and will be further addressed below. The finding that prominence facilitated integration processes is consistent with results from Morris and Folk (1998) but departs from our previous study (Birch \& Rayner, 1997) of syntactic focus effects, in which processing times were longer for focused words. The results of our present Experiment 3 indicate that the divergent results of our present and previous (Birch \& Rayner, 1997) studies cannot be attributed to the type of prominence manipulation. That is, our present results diverged not only when we used more subtle manipulations of prominence, as in the present Experiments 1 and 2, but also when we used the same focusing phrases used in our earlier Experiment 1. A more likely source of the divergent results would seem to be in the nature of the nonprominent conditions. Perhaps the nonfocus sentences in our earlier study, which not only removed the target words from focus but also deemphasized them, somehow enabled easier integration of the target words, producing faster second-pass times than in the focus condition. Alternatively, the focus sentences in our earlier study may have been harder to read, due to ambiguities in interpretation compared with the nonfocus sentences. (Note, however, that this ambiguity explanation is not consistent with the finding in the present Experiment 3 of faster reading times for the focus condition.) In any case, it is now clear that because the focus and nonfocus sentences in Birch and Rayner (1997) contained differences beyond the presence versus absence of a focusing phrase, we cannot attribute results from that study to the effects of focus by itself. Additional research will be needed to determine whether interpretation differences, de-emphasis, or some other factor led to the faster processing times for the nonfocus condition in that study.

The present study extends in a number of ways Morris and Folk's (1998) finding that prominent concepts are more easily integrated in a reader's discourse model. 
First, as previously indicated, the nonfocus condition in their study involved not only removing the target word from the focusing phrase but also placing it in a subordinate clause (and placing an alternative noun in focus). It is therefore possible that their results, like our previous results (Birch \& Rayner, 1997), arose at least in part from syntactic de-emphasis rather than from prominence alone. In fact, since the focus conditions in our previous Experiment 1 and those in Morris and Folk's Experiment 2 were very similar but had nonfocus conditions involving different types of de-emphasis, it may be that those studies together tell us less about differing effects of focus than about differing effects of syntactic de-emphasis. Other differences between the comparison conditions may have contributed to the results obtained in Morris and Folk's study, as well as in Birch and Rayner (1997). For instance, the sentences from Morris and Folk may have been more complex, slowing reading times in the nonfocus condition in comparison with those in the focus condition. Clearly, the use of a nonfocus comparison condition that either de-emphasizes the target word or contains any other differences from the focus condition besides the removal of the focusing phrase introduces potential influences on reading times. Since the nonfocus condition in our present Experiment 3 did not involve placing an alternative noun in focus, de-emphasizing the target, or any other sentence structure differences, we are more confident that syntactic prominence in itself facilitates text-integration processes. Moreover, this conclusion applies not only when prominence is manipulated with specific focusing phrases (as in Experiment 3) but also when it is manipulated more subtly, on the basis of predicate (vs. prenominal) or direct-object (vs. indirect-object) position (as in the present Experiments 1 and 2). This ease of integration into the discourse model may be the source of the enhanced accessibility of and memory for prominent concepts reported in studies using probe recognition, naming time, and anaphor resolution measures (e.g., Birch et al., 2000; Klin et al., 2004; McKoon, Ratcliff, et al., 1993).

The present results depart from previous eyetracking results in indicating faster encoding for syntactically prominent concepts. In the previous studies (Birch \& Rayner, 1997; Morris \& Folk, 1998; Ward \& Sturt, 2007), there were generally no significant differences observed in initial processing times (e.g., first-fixation times, gaze duration, and first-pass reading times) between prominent and less prominent concepts. (The exception, in Birch \& Rayner's [1997] Experiment 2, indicated longer first-pass times, but only for entire phrases focused by a context question). It is possible that insufficient power prevented initial processing-time differences from being observed in these previous studies. Indeed, with the exception of the phrase-focus cases in Birch and Rayner's (1997) Experiment 2, gaze durations were numerically faster for the focused targets in all of these studies. However, another possible source for the different results in initial encoding is the difference in the nature of the nonprominent conditions between the present and previous eyetracking studies. As already indicated, whereas the nonprominent conditions in the previous studies all involved syntactic de-emphasis and/or the presence of a clear focus on other constituents, this was not the case in the present experiments. In the present Experiments 1 and 2, focusing devices were not used at all; rather, targets were relatively more or less prominent on the basis of their syntactic positions in phrases or clauses. In Experiment 3, the nonprominent condition involved the lack of a focusing phrase but not a shift in focus to an alternative concept (nor any other type of de-emphasis). As such, it seems that the difference in salience between the prominent and nonprominent targets in the present experiments was likely smaller than the difference in the previous experiments. Intuitively, a smaller difference in prominence might seem less likely to yield a significant effect on any measure; however, it may be the case that syntactic de-emphasis (or the presence of a clear focus elsewhere in the sentence) simply affects encoding processes differently than do the smaller variations in prominence that were present in our study. Put another way, it may be that the presence of syntactic de-emphasis or a clear focus elsewhere, as used in the previous eyetracking studies, ultimately obscured to a certain degree the effects of prominence on early encoding processes. As already indicated, other differences between the prominent and nonprominent conditions besides syntactic de-emphasis may have affected the results in these experiments as well. We therefore conclude that previous failures to observe an effect of prominence on early encoding measures resulted from factors other than prominence that varied between conditions, and that the present finding of an effect of prominence on early encoding processes is reliable.

As noted previously, the finding that prominent constituents are encoded and/or accessed more quickly was not what we expected. Previous studies with the same manipulations used in our present Experiments 1-3 had provided evidence that the syntactically prominent constituents were more accessible and more memorable (Birch et al., 2000; McKoon, Ratcliff, et al., 1993). McKoon, Ratcliff, et al. proposed that one reasonable source of heightened accessibility would be increased processing during reading (i.e., longer reading times and/or more fixations), and that is the result we expected. Instead, the present experiments indicate that syntactic prominence leads to reduced processing time during reading (for both early encoding and integration processes). Therefore, the enhanced accessibility and memory observed in previous studies apparently did not result from increased processing time for prominent concepts; rather, prominence facilitated encoding and integration of constituents as well as accessibility and memory.

The conclusion that prominent constituents are encoded and/or accessed more quickly during reading is consistent with Cutler and Fodor's (1979) conclusion that focus speeds up lexical access during comprehension of speech. Their conclusion was based on faster auditory-phonememonitoring reaction times for word targets focused by a preceding question. In discussing such an effect, Cutler (1976b) proposed that listeners of speech expect prosodically prominent words to indicate the focus of information, and Cutler and Fodor further suggested that 
this expectation leads listeners to "actively search . . . for sentence focus" (p. 56). This active search would result in increased attentional resources being devoted to constituents that are indicated by the prosodic contour to fall within the focused position. This position, states Cutler (1976a), is the "semantically most central portion of the utterance" (p. 141), and faster phoneme-monitoring times indicate "greater attention paid to the stressed and/or focused elements" (p. 141). Our results are consistent with the proposal that variations in syntax provide cues to informational prominence contours for readers in a manner that is similar to the way that prosodic contours provide cues for listeners, and that such cues prompt increases in attentional resources for the constituents signaled by syntax as more important. These increases in attention would enable facilitation of early encoding for the important constituents - as well as easier integration of them into the discourse model and heightened accessibility upon subsequent reference, among other benefits. Thus, readers apparently heed the "mental processing instructions" (Givón, 1992) provided by indicators of prominence at the earliest stages of sentence processing.

\section{AUTHOR NOTE}

The research was supported by Grant HD26765 from the National Institutes of Health. We thank Gail McKoon for sharing materials from McKoon, Ratcliff, Ward, and Sproat (1993) with us. We also thank Robin Morris and three anonymous reviewers for their helpful comments on earlier drafts of the manuscript. Correspondence concerning this article should be addressed to S. Birch, Department of Psychology, College at Brockport, SUNY, Brockport, NY 14420 (e-mail: sbirch@ brockport.edu).

\section{REFERENCES}

ANDERSON, S. R. (1971). On the role of deep structure in semantic interpretation. Foundations of Language, 7, 387-396.

Birch, S. L., Albrecht, J. E., \& Myers, J. L. (1998, November). Eye movement measures of syntactic focus effects on pronoun resolution. Paper presented at the annual meeting of the Psychonomic Society, Dallas, TX.

Birch, S. L., Albrecht, J. E., \& Myers, J. L. (2000). Syntactic focusing structures influence discourse processing. Discourse Processes, 30, 285-304. doi:10.1207/S15326950dp3003_4

Birch, S. L., \& GARNSEY, S. M. (1995). The effect of focus on memory for words in sentences. Journal of Memory \& Language, 34, 232-267. doi:10.1006/jmla.1995.1011

BirCH, S. [L.], \& RAYNER, K. (1997). Linguistic focus affects eye movements during reading. Memory \& Cognition, 25, 653-660.

Blutner, R., \& Sommer, R. (1988). Sentence processing and lexical access: The influence of the focus-identifying task. Journal of Memory \& Language, 27, 359-367. doi:10.1016/0749-596X(88)90061-7

BrédArT, S., \& Docquier, M. (1989). The Moses illusion: A follow-up on the focalization effect. Cahiers de Psychologie Cognitive/Current Psychology of Cognition, 9, 357-362.

Brédart, S., \& Modolo, K. (1988). Moses strikes again: Focalization effect on a semantic illusion. Acta Psychologica, 67, 135-144. doi:10.1016/0001-6918(88)90009-1

Carpenter, P. A., \& Just, M. A. (1977). Integrative processes in comprehension. In D. LaBerge \& S. J. Samuels (Eds.), Basic processes in reading: Perception and comprehension. Hillsdale, NJ: Erlbaum.

Cutler, A. (1976a). Beyond parsing and lexical look-up: An enriched description of auditory sentence comprehension. In R. J. Wales \& E. Walker (Eds.), New approaches to language mechanisms: A collection of psycholinguistic studies (pp. 133-149). Amsterdam: NorthHolland.
Cutler, A. (1976b). Phoneme-monitoring reaction time as a function of preceding intonation contour. Perception \& Psychophysics, 20, 55-60.

CUTLER, A., \& FodOR, J. A. (1979). Semantic focus and sentence comprehension. Cognition, 7, 49-59. doi:10.1016/0010-0277(79)90010-6

EhrLich, K., \& RAYNer, K. (1983). Pronoun assignment and semantic integration during reading: Eye movements and immediacy of processing. Journal of Verbal Learning \& Verbal Behavior, 22, 75-87. doi:10.1016/S0022-5371(83)80007-3

EngelKamp, J., \& Zimmer, H. D. (1982). The interaction of subjectivization and concept placement in the processing of cleft sentences. Quarterly Journal of Experimental Psychology, 34A, 463-478.

FoRAKER, S., \& McElREE, B. (2007). The role of prominence in pronoun resolution: Active versus passive representations. Journal of Memory \& Language, 56, 357-383. doi:10.1016/j.jml.2006.07.004

Garrod, S., Freudenthal, D., \& Boyle, E. (1994). The role of different types of anaphor in the on-line resolution of sentences in a discourse. Journal of Memory \& Language, 33, 39-68. doi:10.1006/ jmla.1994.1003

GARrod, S., \& SANFORD, A. J. (1994). Resolving sentences in a discourse context: How discourse representation affects language understanding. In M. A. Gernsbacher (Ed.), Handbook of psycholinguistics (pp. 675-698). San Diego: Academic Press.

Gergely, G. (1992). Focus-based inferences in sentence comprehension. In I. A. Sag \& A. Szabolcsi (Eds.), Lexical matters (pp. 209-240). Stanford, CA: Center for the Study of Language and Information.

Givón, T. (1992). The grammar of referential coherence as mental processing instructions. Linguistics, 30, 5-56. doi:10.1515/ling.1992 .30.1.5

Halliday, M. A. K. (1967). Notes on transitivity and theme in English: Part 2. Journal of Linguistics, 3, 199-244. doi:10.1017/ S0022226700016613

Hirotani, M., Frazier, L., \& Rayner, K. (2006). Punctuation and intonation effects on clause and sentence wrap-up: Evidence from eye movements. Journal of Memory \& Language, 54, 425-443. doi:10.1016/j.jml.2005.12.001

KINTSCH, W. (1974). The representation of meaning in memory. Hillsdale, NJ: Erlbaum.

KInTSCH, W. (1988). The role of knowledge in discourse comprehension: A construction-integration model. Psychological Review, 95, 163-182. doi:10.1037/0033-295X.95.2.163

KINTSCH, W. (1992). How readers construct situation models for stories: The role of syntactic cues and causal inferences. In A. F. Healy, S. M. Kosslyn, \& R. M. Shiffrin (Eds.), Essays in honor of William K. Estes: Vol. 2. From learning processes to cognitive processes (pp. 261-278). Hillsdale, NJ: Erlbaum.

Klin, C. M., Weingartner, K. M., Guzmán, A. E., \& Levine, W. H. (2004). Readers' sensitivity to linguistic cues in narratives: How salience influences anaphor resolution. Memory \& Cognition, 32, 511-522.

LANGFord, J., \& Holmes, V. M. (1979). Syntactic presupposition in sentence comprehension. Cognition, 7, 363-383. doi:10.1016/0010 $-0277(79) 90022-2$

McKoon, G., Ratcliff, R., Ward, G., \& Sproat, R. (1993). Syntactic prominence effects on discourse processes. Journal of Memory \& Language, 32, 593-607. doi:10.1006/jmla.1993.1030

McKoon, G., Ward, G., Ratcliff, R., \& Sproat, R. (1993). Morphosyntactic and pragmatic factors affecting the accessibility of discourse entities. Journal of Memory \& Language, 32, 56-75. doi:10.1006/ jmla.1993.1004

MoravcsiK, J. E., \& Healy, A. F. (1998). Effect of syntactic role and syntactic prominence on letter detection. Psychonomic Bulletin \& Review, 5, 96-100.

Morris, R. K., \& FolK, J. R. (1998). Focus as a contextual priming mechanism in reading. Memory \& Cognition, 26, 1313-1322.

Myers, J. L., \& O'Brien, E. J. (1998). Accessing the discourse representation during reading. Discourse Processes, 26, 131-157. doi:10.1080/ 01638539809545042

Paterson, K. B., Liversedge, S. P., Filik, R., Juhasz, B. J., White, S. J., \& RAYNER, K. (2007). Focus identification during sentence comprehension: Evidence from eye movements. Quarterly Journal of Experimental Psychology, 60, 1423-1445. doi:10.1080/ 17470210601100563

RAYNER, K. (1998). Eye movements in reading and information pro- 
cessing: 20 years of research. Psychological Bulletin, 124, 372-422. doi:10.1037/0033-2909.124.3.372

RAYNER, K. (2009). Eye movements and attention during reading, scene perception, and visual search. Quarterly Journal of Experimental Psychology, 62, 1457-1506.

Rochemont, M. S., \& Culicover, P. W. (1990). English focus constructions and the theory of grammar. New York: Cambridge University Press.

ScInTo, L. F. (1978). Relation of eye fixations to old-new information in texts. In J. W. Senders, D. F. Fisher, \& R. A. Monty (Eds.), Eye movements and the higher psychological functions (pp. 175-194). Hillsdale, NJ: Erlbaum.

Singer, M. (1976). Thematic structure and the integration of linguistic information. Journal of Verbal Learning \& Verbal Behavior, 15, 549558. doi:10.1016/0022-5371(76)90049-9

Sturt, P., Sanford, A. J., Stewart, A., \& Dawydiak, E. (2004). Linguistic focus and good-enough representations: An application of the change-detection paradigm. Psychonomic Bulletin \& Review, 11, 882-888.

WARD, P., \& STURT, P. (2007). Linguistic focus and memory: An eye movement study. Memory \& Cognition, 35, 73-86.

Wilson, D., \& SPERBER, D. (1979). Ordered entailments: An alternative to presuppositional theories. In C. K. Oh \& D. A. Dineen (Eds.), Syntax and semantics: Vol. 11. Presupposition (pp. 299-323). New York: Academic Press.

Zimmer, H. D., \& Engelkamp, J. (1981). The given-new structure of cleft sentences and their influence on picture viewing. Psychological Research, 43, 375-389. doi:10.1007/BF00309223

\section{NOTES}

1. As will be clear from the literature review, a number of empirical studies have demonstrated enhanced processing for syntactically prominent entities, confirming previous linguistic analyses that had identified these entities as prominent. Aside from McKoon, Ratcliff, et al.'s (1993) study, much of this empirical work has involved the use of focus structures to assign prominence. The concept of syntactic prominence overlaps - but is not fully synonymous - with the concept of sentence focus. A common definition of focus is that it is the most important and emphasized constituent of a sentence and that it conveys new information (see, e.g., Halliday, 1967). Although focused information is indeed prominent information, we use the more general term prominent to include other syntactic manipulations that also indicate (relative) importance within a sentence. Moreover, across the three experiments that we report, we used two other types of syntactic manipulations in addition to focus structures to vary prominence. All three types of syntactic manipulations used in these experiments have been shown in previous linguistic and empirical studies to be effective indicators of prominence.

2. Although total time effects may not indicate integration processes alone, most researchers in the field agree that they mainly reflect integration processes. By and large, we maintain this standard interpretation throughout the manuscript.

3. Anderson (1971) suggested that the relatively greater prominence of direct over indirect objects relates to the fact that, in English, indirect objects may be optional; however, sentences in which the verb requires an indirect object must also have a direct object.

4. When a target region was larger than a single word, first-pass reading has been used instead of gaze duration (Rayner, 1998, 2009).

5. The lack of a first-fixation time effect could be due to the fact that two words comprised the target region.

6. Although no significant differences emerged in the immediate probe recognition task between focus and neutral conditions (exemplified in Condition A vs. Condition C in Example 6), differences were observed between these conditions on other measures. Readers made significantly more references in a sentence-continuation task (Birch et al., 2000, Experiment 1) and had significantly faster responses in a delayed probe recognition task (Experiment 4) for the focused targets than for the neutral targets. Thus, facilitatory effects of focus were observed in tasks other than the immediate probe recognition task that revealed only inhibitory effects of syntactic de-emphasis. The lack of difference between focus and neutral conditions in immediate probe recognition was attributed in part to a floor effect in reaction times.

7. These experiments were originally developed to compare two types of anaphoric reference, and the results were originally reported in a conference presentation (Birch, Albrecht, \& Myers, 1998).

8. This reanalysis was based on a subset of 16 items from Experiments $3 \mathrm{~A}$ and $3 \mathrm{~B}$, and it produced the following focus-nonfocus effects. Focused targets were $19 \mathrm{msec}$ faster than nonfocused targets for firstfixation time. For gaze duration, the effect was $35 \mathrm{msec}$, and for total reading time, the effect was $25 \mathrm{msec}$. The difference in total number of fixations was 0.02 , which did not replicate the effect found with the total set of items.

(Manuscript received March 16, 2009; revision accepted for publication January 28, 2010.) 